\title{
As MoEdas DAS MUlHeres IMPERIAIS
}

Taís Pagoto Bélo ${ }^{1}$

RESUMO

Este artigo visa expor a imagem pública de algumas mulheres do final da República e início do Império através de exemplares de moedas que datam do período do Principado, que se estabeleceu com Augusto (27 a.C.), até a morte de Nero (68 d.C.). Tem-se o intuito de ilustrar como, nesse período, essas mulheres melhoraram sua visibilidade na vida pública, por meio de afazeres ligados à família imperial, que as levaram ao Patronato e, consequentemente, à autopropaganda, englobando suas imagens em moedas, como uma forma de se demonstrar poder.

As mulheres dessa época eram restritas à vida privada e doméstica devido à existência da patria potestas, que era significante e marcava as relações de poder do pai dentro da família romana, classificando a mulher como desigual ao homem. A conquista das mulheres em terem seus nomes lembrados, através de estátuas, placas e moedas, era algo recente no final da República e início do Império, tendo sido estabelecida através do Patronato. A lembrança da pessoa, dessa forma, era importante e poderia repercutir por gerações na família.

As moedas com representações das mulheres imperiais possibilitam não somente reconstruir cronologicamente a existência delas na história, mas também revelam que elas eram ativas na vida pública.

PALAVRAS-CHAVE

Mulheres imperiais; Moedas; Roma.

\footnotetext{
${ }^{1}$ Pós-doutoranda do Museu de Arqueologia e Etnologia da Universidade de São Paulo. Pesquisa com apoio da agência de fomento, FAPESP. E-mail: taispbelo@usp.br.
} 
Mare Nostrum, ano 2020, v. 11, n. 1 .

\section{Introdução}

Ao caminhar por Roma, fosse em uma basílica, fosse em uma praça, lá estariam estátuas, afrescos e placas de figuras imperiais deificadas para serem apreciadas pela população. Além disso, as imagens dessas pessoas circulavam cotidianamente mediante um objeto comum: a moeda, a qual demonstrava uma face da percepção do poder, que refletia o que a pessoa fez ou iria fazer (Tuner, 2007, p. 5). Destacam-se também o valor e o fato de que as moedas não eram efêmeras, pois circulavam mesmo depois da morte do imperador que as havia cunhado e podiam continuar circulando por mais de cem anos depois (Porto, 2018, p. 142), comprovando que era um objeto que contribuía à memória daquele que a tinha cunhado.

Muitos desses rostos eram de mulheres ligadas à família imperial, como: a mãe do imperador, sua esposa, suas filhas e até de suas irmãs. A consideração de se ter como lembrar de alguém pela eternidade marcava a estima da memória para essa sociedade, além de ser um marco de status familiar. ${ }^{2}$ As mulheres imperiais eram sempre lembradas como modelos apropriados de esposas. A figura delas em moedas, por exemplo, de alguma forma, expressava que elas sustentavam uma prosperidade imperial, felicidade matrimonial, segurança, lealdade e outras virtudes.

Desse modo, o intuito deste artigo é demonstrar o início de um estudo que tem como finalidade exemplificar, através de moedas, o alcance público das mulheres romanas, citando as primeiras mulheres da República que tiveram seus rostos cunhados, como Fúlvia, e aquelas que compuseram a família Júlio-Claudiana, desde quando se estabeleceu o Principado, com o poder de Augusto (27 a.C.) até a morte de Nero (68 d.C.).

\section{As mulheres imperiais}

$\mathrm{O}$ ato de retratar estas mulheres em moedas, bem como de outras formas, foi uma inovação à vida pública delas, apesar de algumas, durante o período mais tardio da República, ainda estarem sob o domínio do poder dos maridos (manus), pois tudo

\footnotetext{
${ }^{2}$ A memória dos personagens romanos estava atrelada ao culto dos ancestrais em Roma e era um elemento forte da religiosidade, que se manifestava de muitas formas, como em procissões funerárias, em exposições de retratos nos pátios das residências senatoriais, etc. A iconografia monetária foi mais uma maneira de mostrar o poder familiar e seu status na sociedade (Florenzano, 2015, p. 16).
} 
permanecia sob o poder (potestas) de seus pais (paterfamilias). As filhas não podiam possuir propriedades ou assinar um contrato. Depois da morte do pai, ficavam independentes (sui iuris), mas, de qualquer modo, eram sujeitas a um tutor (Rawson, 2006, p. 332).

Durante o Império, alguns critérios para a vida dessas mulheres continuaram. Alguns casamentos ocorriam ainda sob a forma de manus, e tudo que a mulher recebia de presente ou de noivado, por exemplo, era investido por seu marido, com exceção de alguns direitos sobre seu dote. Além disso, o que ela recebia da vontade de seu marido dependia da sua generosidade (Gardner, 1990, pp. 11-15; Bélo \& Funari, 2017, pp. 76$77)$.

O pater ${ }^{3}$ também poderia ser o avô ou até o bisavô, os quais possuíam a potestas de algumas pessoas, como da mulher e dos filhos. Diante da morte do pater, seus filhos e esposa tinham que ficar sob o controle de outro tutor (alieni iuris) ou independentes, sob a proteção da justiça do Estado. O filho adulto se tornava o paterfamilias e a mãe, materfamilias (Gardner, 1990, pp. 5-7). Os pais tinham o poder de decisão sobre a propriedade e o destino das mulheres e das crianças, ${ }^{4}$ que eram consideradas objetos de sua posse, assim como os animais e as plantações (Omena, 2007; Sampaio \& Venturini, 2009, p. 2; Bélo \& Funari, 2017, p. 77).

Como se pode perceber, as mulheres da República, antes de iniciarem atividades ligadas ao Patronato, eram restritas à vida privada e doméstica. A própria patria potestas é significante e é uma marca das relações de poder do pai dentro da família romana, classificando a mulher como desigual ao homem. A ideia de identidade de gênero era legitimada diferentemente, com valores desiguais entre homens e mulheres, o que era aceito pelos dois grupos e internalizado mediante atividades cotidianas (Revell, 2016, p. 15; Bélo \& Funari, 2017, p. 78).

A conquista do espaço público provavelmente aconteceu porque mulheres, como Lívia e Agripina, muitas vezes, tiveram de lidar com demandas de atividades que estavam fora dos limites dos afazeres da casa para preencher as responsabilidades familiares,

\footnotetext{
${ }^{3} \mathrm{O}$ poder do pater sobre a familia tem origem primitiva na sociedade romana, de quando a proteção do grupo dependia de esforços do próprio grupo e não das regras da lei (Gardner, 1990, p. 6).

${ }^{4}$ No caso de impureza das filhas, por exemplo, o pater poderia condená-las à morte (Gardner, 1990, p. 7).
} 
momento em que elas entraram em contato com assuntos domésticos e públicos (Fischler, 1994, p. 122).

A aquisição das mulheres em terem seus nomes lembrados por meio de estátuas, placas e moedas era algo recente, do final da República e início do Império. Ela foi estabelecida mediante o Patronato, isto é, quando um indivíduo provia uma doação vinda de suas riquezas em benefício da cidade ou de um pequeno grupo dentro dela (Meyers, 2012, p. 461) e, em troca, recebia uma homenagem (Bélo \& Funari, 2017, p. 79).

O primeiro estudioso a utilizar os termos "Patronato" e "solidariedade voluntária" foi Fustel de Coulanges (1890), e descreveu as relações de obrigações mútuas, como fides (confiar em outro), que era a mais comum. Tanto os favores (beneficia), serviços, ou marcas de gratidão (officia), necessariamente implicavam em uma ética de reciprocidade que influenciava o envolvimento das pessoas e também sua reputação, que era medida de acordo com suas respectivas obrigações privadas e habilidades em preservar as redes de relações dos patronos(as), passando esse ato de geração para geração. A troca de serviços e benefícios não pertencia apenas à moralidade privada, mas também à moralidade pública de Roma (Deniaux, 2006, pp. 401-402).

Para Bielman (2012) o conceito de "patronato" (do latim patronus, patrono) está ligado a um suporte dado por uma pessoa influente. Não tendo um equivalente dessa palavra em português, o termo mais próximo seria "evergetismo" (do grego euergetes, benfeitor), que significa todos os atos de boa vontade de um indivíduo aos outros cidadãos. O termo descreve o papel público feito por um indivíduo enraizado em um sistema de referência masculino. Esses termos são de difícil aplicação para as mulheres, ou seja, no latim a palavra patrona é derivada do masculino patronus, que é formado por pater e se refere essencialmente a autoridade masculina (Bielman, 2012, p. 239).

Ao mencionar a ação do Patronato, Hermelrijk (2015) menciona a munificência cívica, comum às pessoas de "bem" romanas. A munificência cívica é geralmente vista como envolvendo duas partes: o beneficiador, quem providencia à comunidade com prédios, entretenimentos, e outros serviços; e os beneficiados, que expressavam seu agradecimento com uma recompensa honrosa e privilégios. Diferentes motivos têm sido sugeridos aos beneficiadores cívicos, ou seja, competição entre a elite, ganho de prestígio social, pressão financeira das cidades, legitimação de leis políticas da elite, os quais mostraram que a munificência cívica seria um fenômeno complexo que serviria à muitos 
propósitos, como promover a união cívica, aliviando a tensão entre a elite próspera e poderosa e aqueles que não pertenciam a ela (Hermelrijk, 2015, p. 112).

A munificência trouxe várias aberturas às mulheres da elite dessa época, através do ofício cívico e do ganho da honra pública. Contudo, o motivo para esse ato poderia ser mais complexo, envolvendo diferenças de prosperidades de famílias, status social, ambição, tradição familiar, sentimentos religiosos e outros, mas a honra parece ser o mais importante. Dessa forma, muitos membros de famílias, conhecidas pelo costume de doação, deveriam se sentir pressionados a fazer o ato de generosidade, uma vez que a munificência garantia a reputação familiar. Em relação às mulheres doadoras, parece que havia uma disputa entre elas, sendo que algumas se tornaram modelos a serem seguidos pelas demais. Sendo assim, a munificência era essencial para a honra, reconhecimento público e para se alcançar a fama póstuma. Em Roma, essa atitude era tomada pelas mulheres ligadas a família imperial, enquanto que nas províncias, esse grupo poderia incluir mulheres livres e aquelas que faziam parte da elite local. Entretanto, o status de tais mulheres não era indicado (Hemerijk, 2015, pp. 165-176).

A munificência cívica contribuía à estabilidade e à atratividade da vida cívica. Os benefícios podiam ser desde o embelezamento das cidades, prédios públicos ou trabalhos de infraestrutura, como estradas e aquedutos. Esses atos de generosidade contribuíam para a aparência e facilidades das cidades, sendo que houve uma grande quantidade de prédios públicos financiados por mulheres, assim como prédios religiosos, templos, além de trabalhos de infraestrutura, como o de suprimento de água, estradas, pontes, muralhas de cidades, comportas, arcos, pavimentação de áreas públicas, estruturas para entretenimentos, bem como teatros, anfiteatros, praças, prédios utilitários e outras instalações; casas de banhos, livrarias, portos, basílicas, chalcidica (galerias), curiae (prédio onde o Senado se reunia), macella (mercados) e outros. Entretanto, de acordo com o estudo feito por Hermelrijk (2015), foi identificado que a maioria dos prédios que receberam patrocínio de mulheres eram construções religiosas, assim como templos e santuários de diversos tipos e tamanhos, além da doação de estátuas de deidades para esses lugares e de toda uma estrutura ligada ao templo como cozinhas, portos, salões com mobília, extensão de cômodos, móveis, colunas, altares, calçadas, portas, bancos e outros equipamentos (Hermelrijk, 2015, pp. 112-119).

Os beneficiários eram homenageados por suas ações de generosidade pública através de inscrições honorárias, em que se omitia a explicação do motivo pelo qual o 
benefício era feito. As mulheres começaram a realizar esse processo no período imperial, quando elas passaram a acumular grandes quantias em dinheiro, as quais muitas vezes eram transmitidas para seus filhos. Entretanto, havia aquelas que decidiram investir em atos públicos de generosidade. O retorno do benefício, geralmente, causava um impacto memorável, desde os menores, como uma placa com o nome, pelo fato de se ter doado óleo para uma casa de banhos, até os maiores, como a construção de um edifício na cidade com o nome da doadora em tamanho gigantesco na fachada, de modo a ser lembrado por gerações. Isso também ajudava a moldar uma personalidade da doadora. O Patronato pode ter sido, assim, uma maneira de reação ao sistema de divisão, que formava um tradicionalismo entre o "público" e o "privado" e que permitiu a essas mulheres entrarem nos negócios urbanos do mesmo modo que os homens, adicionando o fato de começarem a serem tidas como exemplos para as outras mulheres. Essas ações foram imprescindíveis para a continuação da linhagem dinástica das famílias a que pertenciam (Meyers, 2012, pp. 463-465; Bélo \& Funari, 2017, p. 83).

As mulheres que doavam fundos para prédios públicos, festas públicas e jogos recebiam como recompensa um retrato de si mesmas em um local proeminente da cidade. Esses retratos poderiam ser em forma de estátuas. As mulheres imperiais recebiam alguma característica física vinda do imperador, já que elas deviam sua posição ao membro da família que exercia a função imperial, o que demonstrava uma coesão entre a família imperial e o projeto de continuação dinástica, além de temas como maternidade, felicidade e fertilidade (Meyers, 2012, pp. 453-461; Bélo \& Funari, 2017, p. 83).

As moedas, assim como as estátuas, davam uma face de poder físico, às vezes realista, outras vezes idealizada, não somente para os imperadores, mas também para todos aqueles que queriam mostrar a fisionomia da importância do poder. As representações monetárias revelavam homens e mulheres que ajudaram a delinear o poder do imperador de certa forma. Contudo, a imagem exposta era aquela que o governo desejava que fosse vista, ou seja, aquela que evidenciasse a harmonia do Estado; a prosperidade e o sucesso; e as virtudes do imperador e sua família. Além disso, essas figuras poderiam cobrir certas crises do governo, como econômicas, atos tirânicos e guerras civis (Brennan, 2007, p. 7).

A recompensa ao doador(a) era demonstrada através de menções em placas que acompanhavam estátuas, por exemplo, como demonstra Hermelrijk (2015). Entretanto, isso não é demonstrado nas moedas, ou seja, as legendas das moedas não esclarecem a 
correlação entre a cunhagem de imagens femininas e o patronato, sugerindo que a moeda poderia não estar ligada diretamente ao patronato, mas que teria um vínculo propagandístico maior e em favor do imperador; ou a moeda seria ligada ao patronato, mas suas legendas não deixariam explícitas este fato; por fim, poderia ocorrer que as duas possibilidades se complementassem, ou seja, que essas mulheres poderiam ser patronas e que suas imagens em moedas aumentariam a recepção pública de suas figuras. Consequentemente, a amostragem de uma figura feminina que tivesse contribuído para o benefício da cidade também seria algo honroso e de orgulho para o imperador, principalmente se ela fizesse parte da família imperial, e, assim, teria a concessão de sua face em moedas.

\section{As mulheres imperiais nas moedas de Roma}

As mulheres imperiais melhoraram sua visibilidade na vida pública por meio de afazeres ligados à família imperial, que as levaram ao Patronato e, consequentemente, à autopropaganda. ${ }^{5}$ Esta incluía a própria imagem em moedas e era uma forma de se demonstrar poder, ${ }^{6}$ tendo em vista que não há dúvidas de que os romanos usavam símbolos, inscrições e imagens em moedas para promover ideias políticas, eventos sociais e religiosos e mensagens militares ou econômicas (Porto, 2014). ${ }^{7}$ Apesar da posição em que essas mulheres se encontravam e de terem de lidar com o patriarcalismo da época, elas alcançaram certa abrangência pública, ficando marcadas na cultura material dessa sociedade.

Elas sabiam do valor da imagem para a autopropaganda. Em uma sociedade, na qual a maioria da população não sabia nem ler e nem escrever, as imagens em moedas tinham uma força e um grande impacto. As ideias e informações embutidas nas imagens que circulavam em sociedades desse tipo chegavam aos usuários de maneira direta e eficaz. Os agentes de produção desses objetos conheciam bem esses mecanismos que

\footnotetext{
${ }^{5}$ Augusto foi o primeiro a se preocupar com a sistematização das imagens junto à política, procurando demonstrar de forma pública suas qualidades militares como divi filius e seus méritos do Estado (Gonçalves, 2014, p. 57), ao colocar a estética a serviço da política (Porto, 2012, p. 17; Porto, 2018, p. 141).

${ }^{6}$ Bater moedas era sinal de autoridade e o direito de fazê-lo era disputado ora pelo Senado, ora por generais que tinham o intuito do poder imperial, ora por Províncias que queriam ser independentes em relação ao poder central (Florenzano, 2015, p. 17).

${ }^{7}$ Os imperadores, principais agentes do poder romano, potencializavam o espaço nas moedas para reforçar sua autoridade, divulgando suas conquistas militares, virtudes e as maneiras como beneficiavam a população (Florenzano, 2015, p. 18).
} 
Mare Nostrum, ano 2020, v. 11, n. 1 .

transformavam as moedas em elementos importantes da propaganda política e faziam o máximo para bem aproveitá-los (Florenzano, 2015, p. 18).

O termo propaganda vem do verbo latino propago (infinitivo: propagare e substantivo propagatio), que tem o significado de ampliar, alargar, estender, difundir, implantar ou prolongar, prorrogar tempos. Propagator era o título de um magistrado, que tinha a função delineada como um dos epítetos de Júpiter, ou seja, aquele que amplia, que engrandece, que conquista o Império (Busino, 1980, pp. 275-276; Gonçalves, 2002, p. 69). Segundo Huici Módenes (1996), propaganda é uma atividade quase consubstancial à política desde os primórdios da humanidade e parece ter nascido ao mesmo tempo que o aparecimento dos primeiros intuitos de organização e de hierarquização social. Assim sendo, a propaganda vem afirmando suas técnicas de persuasão, que podem ir desde a extrema intimação física até as mais elaboradas construções verbais, através da retórica. Entretanto, nem sempre a persuasão é sinônimo de manipulação, mas de convencimento e de resultar em certas condutas construídas sobre a realidade (Huici Módenes, 1996, pp. 21-42; Gonçalves, 2002, pp. 70-71).

Para Marta Sordi (1974), a propaganda sempre é feita de forma oculta, através de uma persuasão sub-reptícia, não é uma simples difusão de notícias, mas de gestos, ações, discursos, imagens, escritas e outras representações artísticas, as quais se propõe a executar uma pressão psicológica sobre um grupo para enfatizar ou desacreditar uma ideia, uma pessoa, um produto, uma política ou uma religiosidade, com intuito de obter consenso (Sordi, 1974, p. 5; Gonçalves, 2002, p. 71). De acordo com Busino (1980), propaganda é um modo de formular, difundir e propagar mensagens tendenciosas para conquistar e/ou manter uma hegemonia através da persuasão, para o uso do poder (Busino, 1980, p. 276; Gonçalves, 2002, p. 73). Para Godechot, a propaganda é a arte da persuasão e sua maior característica é ser um processo temporário (Godechot, 1952, p. 515). Para Bobbio (1986) é um esforço sistemático e consciente para influenciar opiniões (Bobbio, 1986, p. 1018; Gonçalves, 2002, p. 74).

Na Antiguidade já se articulavam os símbolos existentes para criarem uma imagem de si para seus súditos, a qual deveria estar de acordo com os padrões culturais aceitos por tal sociedade. As imagens necessitavam de uma comunicação calculada, com efeitos precisos, que desvendavam uma parte da realidade, pois o poder também deve sua existência à apropriação de informações, dos conhecimentos para governar, administrar e para dominar (Balandier, 1980, p. 13; Gonçalves, 2002, p. 58). Através da propaganda 
os imperadores romanos conseguiram prestígio, consideração, fidelidade, adesão e obediência (Busino, 1980, p. 276; Gonçalves, 2002, pp. 59-60).

A propaganda ajudava a justificar o governo de um só e sua proeminência sobre os outros seres humanos. Além de que a justificativa do poder derivava da lei, da estrutura constitucional garantida pela plebe, pelo Senado e da natureza que o soberano demonstrava ter. O sentido era que o imperador mostrasse ser melhor aos súditos e deter a anuência divina para seu culto (Mazza, 1986, pp. 3-93; Gonçalves, 2002, pp. 59-60). Praticar as virtudes e divulgar essa prática se transformavam em importantes ações propagandísticas, que davam coesão ao sentido público, propagando a continuidade do sistema imperial e seus valores, além da ligação do Príncipe com os súditos e deuses (Hidalgo de la Vega, 1995, pp. 19-25 e 108-125; Gonçalves, 2002, pp. 59-60).

Eram das moedas que provinham as faces e proclamavam, antes de outras artes, a publicidade e os valores daqueles que governavam o mundo romano. Entretanto, na realidade do império, deve-se admitir que as moedas eram, primordialmente, importantes para seu papel primário, que estava ligado à circulação, em especial, entre os soldados, enquanto no império tardio, circulava entre os burocratas (Brennan, 2007, p. 8). Esse fato pode sugerir que esses grupos seriam aqueles em que a propaganda deveria estar em primeira instância e aos quais a faceta do poder deveria ter o desígnio de alcançar. Entretanto, não se sabe qual foi o tipo de recepção tomada por cada imagem feminina, pois esse é um tipo de agência pouco comentada em fontes textuais e que não deixou marcas em fontes materiais, mas a quantidade de representações e a longevidade das imagens de Lívia, por exemplo, demonstram extrema aceitabilidade de sua honra, tanto para instituições políticas, como o Senado, que permitiu a cunhagem de suas moedas, quanto para o público, demonstrado pela cunhagem de suas moedas em províncias do Leste e Oeste e da existência de outros tipos de representações suas.

Em relação a escolha do tema de uma moeda, ou quem decidia a cunhagem de tal moeda, Levick (1982) e Wallace-Hadrill (1986) concordam que as moedas deveriam ser escolhidas por oficiais do governo (tresviri monetales, ${ }^{8}$ três magistrados de cunhagem),

\footnotetext{
${ }^{8}$ Roma começou a produzir suas próprias moedas seguindo os modelos grego, no final do século IV a.C. O lugar de cunhagem de Roma era administrado por triumviri monetales, ou seja, três magistrados de cunhagens, que eram responsáveis pelo modelo, desenho e emissão das moedas. Eles eram escolhidos pelos cônsules, que, geralmente, acatavam parentes ou clientes. A escolha dos tipos de moedas da República foi bem conservadora, aderida ao intuito de promover Roma, com sua personificação feminina como cidadeestado e com deuses e deusas do panteão romano. No início do século II a.C. esses magistrados de cunhagem começaram a querer se promover colocando seus nomes em denários romanos de prata. No
} 
por um secretário (a rationibus, ministro financeiro encarregado do tesouro imperial) ou por outros oficiais elevados, que queriam honrar o imperador. Sutherland (1986) não concorda com esse posicionamento em relação aos tresviri monetales. Para Sutherland, essa tarefa deveria ser feita por um oficial de posição mais elevada e deveria ter uma audiência com o Senado e o exército para esse tipo de escolha. Provavelmente, nas províncias essa responsabilidade ficaria a cargo das elites locais e dos magistrados de cunhagem, com a intensão da representação ser aceita pelo governo de Roma, com o intuito de lisonjear o imperador (Harvey, 2020, pp. 10-11). ${ }^{9}$

Entretanto, a escolha de como as imagens femininas deveriam aparecer tanto em moedas, como em outras representações, como estátuas, pertencia a outros critérios. Júlia, por exemplo, teria a liberdade para escolher suas roupas e cabelos, mas era seu pai quem controlava a última aprovação de suas representações, com vistas a garantir que suas imagens sobrevivessem. Desse modo, ela sempre aparecia com o mesmo tipo de cabelo severamente modesto igual ao de sua madrasta, Lívia (Wood, 1999, p. 20). O tipo de cabelo ligava as mulheres à certo período em particular e tipos de cabelos idealizados, conectavam os indivíduos a um classicismo genérico e um senso de valor social conservador. Contudo, entende-se que as identidades honorárias eram construídas pelo visual e por pequenos textos, que se repetiam desde que a os primeiros tinham funcionado socialmente, construindo, assim, uma confiança sobre aquele tipo, resultando na replicação e constante repetição, desde que fossem elaborados de forma que sustentasse as preferências sociais, sendo possível classificar essas mulheres como da família imperial, as unificando em uma ideologia da elite-que clamavam por um conjunto compartilhado de valores e legitimidade das categorias governamentais (Trimble, 2011, pp. 192-202).

Todavia, a imagem nunca corresponde ao que a pessoa é em si, pois atribui-se qualidades físicas ou morais que podem ser aumentadas ou desonradas, mutáveis, transformadas e plenas de significados que lhes são atribuídas de acordo com as lembranças, as quais são estabelecidas, mas que são também ligadas ao imaginário, que pode ser mobilizador e evocador de imagens, utilizando o simbólico que pressupõe a capacidade imaginária. A imagem é formada a partir de um eixo real, sendo que o

mesmo século as moedas começaram não só a ter seus nomes como os de ancestrais famosos e deuses associados a suas famílias (Harvey, 2020, p. 33)

${ }^{9}$ Harvey (2020) cita esse tema como se ainda não houvesse uma conclusão definitiva entre os estudiosos sobre quem era responsável por tais escolhas. 
imaginário traduz a representação mental em que o exterior é percebido (Laplantine \& Trindade, 1997; Gonçalves, 2002, p. 57).

Fúlvia, viúva de Clodio, o demagogo, com o qual teve uma filha chamada Clodiaprimeira esposa de Otávio César-, foi a terceira esposa (Harvey, 2020) de Marco Antônio, e ele, seu terceiro marido. Ela foi a primeira romana a ter sua imagem retratada em moedas, sendo representada em várias moedas provincianas da Frígia, tanto é que a cidade de Eumenéia trocou de nome em sua homenagem, ${ }^{10}$ durante o ano 41 a.C. Durante a República, mulheres como Tanaquil, Cornélia e a própria Fúlvia, foram as que começaram a ter mais liberdade devido às promoções conquistadas por seus maridos, ou seja, nenhuma delas tinha um poder autônomo para se promover (Zager, 2014, p. 36). Sendo assim, elas se tornaram participantes ativas na glorificação de suas famílias, de modo que o registro de suas imagens em moedas e em outras representações simbolizou um modo de homenageá-las e de ostentar a família.

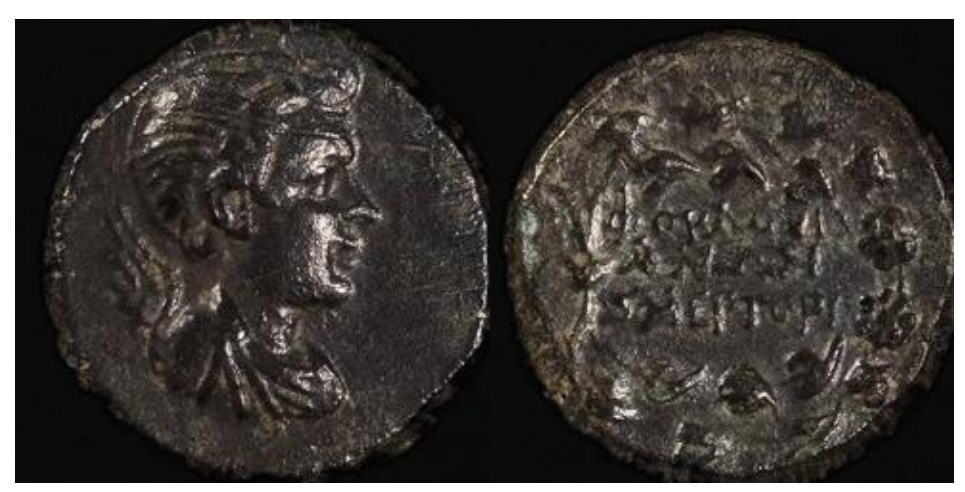

Fig. 01. Moeda de bronze, datada de 40 - 41 a.C., cunhada em Eumenéia, Frígia, de 4,83g com Fúlvia no anverso. $^{11}$

Créditos: @ ) Harvard Art Museums/Arthur M. Sackler Museum, David M. Robinson Fund.

Ao se referir a Fúlvia, Plutarco, escritor grego do primeiro século depois de Cristo, critica o comportamento dela e demonstra que ela não tinha o interesse de fiar, de

\footnotetext{
${ }^{10}$ Esta informação é encontrada em trabalhos como o de Zager (2014) e Harvey (2020) sem maiores explicações de como ocorreu a troca do nome da cidade em questão.

${ }^{11}$ Referência: RPC I, 3140; n. do objeto: 2002.232.2. Proveniência: CNG 61, 25 September 2002, lot 297. (https://www.harvardartmuseums.org/art/141256, recuperado em 09 de novembro, 2019).
} 
administrar o lar ou mesmo de dominar um marido que não tivesse ambição para a vida pública, citando que seu real desejo seria dominar aqueles que governavam ou aqueles que comandavam. Mediante essa observação, o autor até critica Cleópatra, por estar em débito com Fúlvia, já que esta ensinou um marido a obedecer a sua mulher (Putarch, Makers of Rome, 10). Plutarco deve ter tido essa interpretação de Fúlvia por conta de sua atitude, que não era esperada para uma matrona romana, ou seja, ela se envolveu nas tramas de seu marido, Marco Antônio.

Segundo Plutarco, enquanto Cleópatra conseguia cativar Antônio completamente, Fúlvia liderava uma rebelião contra Otávio César para defender os interesses de seu marido. Antônio recebeu a notícia que Fúlvia e seu irmão Lúcio juntaram forças contra Otávio, mas foram derrotados e expulsos da Itália. No caminho para derrotar Labieno, comandante do exército da Pártia que estava se tornando o mestre da Ásia, Antônio ainda recebeu notícias de Fúlvia, cheia de lamentações, o que fez com que ele mudasse seus planos e fosse ao encontro dela. No caminho, Antônio ficou sabendo que a causa de todo o transtorno com Otávio era culpa de Fúlvia. Por essa razão, Plutarco a caracteriza como teimosa e como uma mulher que adorava se intrometer em assuntos políticos, além de indicar que a única forma de Fúlvia fazer com que Antônio largasse Cleópatra era causando hostilidades. Entretanto, Fúlvia adoeceu em seu percurso para se encontrar com Antônio em Sicyon e morreu. Esse evento fez com que houvesse uma reconciliação entre Otávio e Antônio, mas Plutarco reproduz de forma a afirmar que o acontecido tinha sido culpa de Fúlvia, enquanto Antônio acreditava que Otávio é quem era o culpado pela guerra. Consequentemente, o resultado foi um acordo no qual Otávio deu os territórios do leste para Antônio e as províncias da África para Lépido, ficando com o restante (Plutarch, Markers of Rome, 28-30).

A morte de Fúlvia levou a uma reconciliação entre Antônio e Otávio, o qual, para selar a harmonia, ofereceu a mão de sua meia irmã, Otávia, viúva de Gaio Marcelo. Ela era mais velha que Otávio e filha de Átia, de um casamento anterior, com Anchoria. Otávia foi caracterizada por Plutarco como uma mulher maravilhosa, bonita, digna e de bom senso (Plutarch, Makers of Rome, 31).

Em suas representações, Otávia era identificada através do papel de boa mãe, o que era uma característica a ser comemorada. Sua posição muito elogiada como um modelo moral foi pouco elusiva, uma vez que até mesmo moedas com sua imagem foram cunhadas apenas durante a vida de Antônio. 

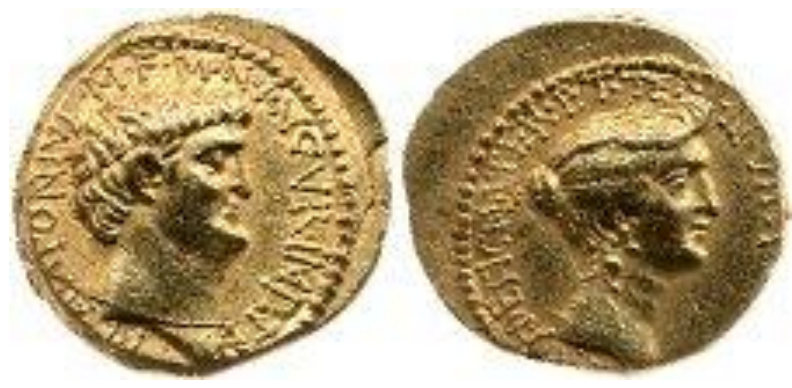

Fig.02. Aureus, datada de 38 a.C., com o rosto de Marco Antônio voltado à direita no anverso, com a inscrição: $M \cdot A N T O N I V S \cdot M \cdot F \cdot M \cdot N \cdot A V G V R \cdot I M P \cdot T E R=$ Marcus Antonius Marcus Filius Marcus Nepos Augurus Imperator Tertium (Marco Antônio, filho de Marcos, neto de Marco, Auguro, ${ }^{12}$ Imperador pela Terceira vez). No reverso está o rosto de Otávia, voltado à direita, com a Inscrição:

COS.DESIGN.ITER $\cdot E T \cdot T E R \cdot I I I \cdot V I R \cdot R \cdot P \cdot C=$ Consul Designatus Iterum TertiumTriumviri Rei Publicae

Constituandae (Nomeado cônsul pela terceira vez no Triunvirato para a restauração do governo). ${ }^{13}$

Créditos: (C) The Trustees of the British Museum ${ }^{14}$

A moeda, com Marco Antônio no anverso e Otávia no reverso, marca a união do casal. Entretanto, representa, especialmente, a harmonia entre Antônio e Otávio, devido ao pacto de Brundísio, em 40 a.C., uma vez que se estabeleceu um acordo político por esse vínculo matrimonial. Além disso, todas as legendas da moeda dizem respeito à vida política de Antônio e nada sobre Otávia, demonstrando o ideal esperado da passividade feminina diante dos laços políticos ali estabelecidos.

Quando Plutarco se refere a Otávia, cita que ela continuou a agir como uma mulher exemplar, ficando em Roma e trabalhando para os benefícios do marido enquanto ele fazia negócios com Cleópatra. As virtudes de Otávia exemplificam a matrona romana

\footnotetext{
${ }^{12}$ Marco Antônio é imperator, augur e triumvir. Augur é aquele que prevê, que reconhece os presságios. Augure é aquele que faz o presságio. O adjetivo é derivado de Augustus, consagrado por áugure ou sob augúrios favoráveis (Martins, 2011, p. 66 e 75).

13 Tradução nossa, com consulta em (https://en.numista.com/catalogue/pieces66597.html, recuperado em 09 de novembro, 2019).

${ }^{14}$ (https://www.britishmuseum.org/research/publications/online_research_catalogues/search_object_detail s.aspx?objectid=3072639\&partid=1\&searchText=Octavia\&numpages $=12 \&$ output=bibliography $\% 2 f ! ! \% 2$ fOR $\% 2 \mathrm{f} ! ! \% 2 \mathrm{f} 6738 \% 2 \mathrm{f} \% \% 2 \mathrm{f} \% 2 \mathrm{f} ! \% 2 \mathrm{fA}+$ catalogue+of+the+Roman+Republican+Coins+in+the+British+ Museum $\% 2 \mathrm{c}+$ with+descriptions+and+chronology+based+on+M.H.+Crawford\%2c+Roman+Republican +Coinage+(1974)\%2f!\%2f\%2f!!\%2f\%2f!!!\%2f\&sortBy=catNumber\&orig=\%2fresearch $\% 2$ fpublications $\% 2$ fonline research catalogues $\% 2$ frussian icons $\% 2$ fcatalogue of russian icons.aspx\&catalogueOnly=T rue\&catparentPageId=29126\&catalogueName=Roman $\% 20$ Republican $\% 20$ Coins $\% 20$ in $\% 20$ the $\% 20$ Britis

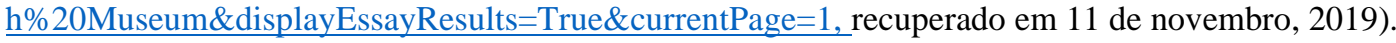


Mare Nostrum, ano 2020, v. 11, n. 1.

ideal, em contraste com o decadente arquétipo da imagem do Oriente de Cleópatra, assegurada pelo ponto de vista romano (Fischler, 1994, p. 118).

Contudo, em qualquer posição tomada por Fúlvia ou Otávia em relação a Marco Antônio, Plutarco coloca como se fosse algo que elas faziam com o intuito de abalar Cleópatra, a qual também era descrita pelo autor como uma mulher que tinha a mesma intenção contra elas, ou seja, demonstrava que ela agia de forma a seduzir Antônio para se voltar contra elas. Plutarco menciona que se Otávia pudesse adicionar o charme que ela tinha diante da sociedade em sua atenção afetuosa, ela poderia ganhar completamente o controle sobre seu marido e fazer com que sua posição ficasse inatingível. Ele afirma, ainda, que Otávia somente se casou com Antônio por questões políticas, pelos interesses de seu irmão, mas Cleópatra, sendo soberana de várias nações, contentava-se em ser sua amante. Mesmo Antônio se negando a ir encontrar Otávia em Atenas, ela continuou a morar em sua casa, cuidando de seus filhos e do filho que teve com Fúlvia, enquanto Otávio achou essa atitude de Antônio ultrajante e quis que Otávia saísse da casa dele, o que foi negado por ela. Enquanto isso, Antônio proclamou Cleópatra a rainha do Egito, de Ciprus, da Líbia e da Síria, além de ter declarado Cesário seu consorte. Para o filho que teve com Cleópatra, Alexandre, deixou a Armênia, Media e Partia; para o filho Ptolomeu, a Síria e a Cilicia. Plutarco não cita a filha do casal, Cleópatra Selene. Continuando sua narração, cita que Antônio envia um recado para Otávia sair de sua casa e ela sai com todos seus filhos, deixando apenas aquele que Antônio teve com Fúlvia, Antillo. Otávio declara guerra a Cleópatra e retira os poderes de Antônio, já que ele os tinha entregue a uma mulher (Plutarch, Makers of Rome, 53-60).

Ao contrário de Otávia, Lívia, esposa de Augusto, foi a mulher da família JúlioClaudiana mais bem representada e seu nome apareceu em portos, mercados e até santuários, além de sua imagem em moedas. Tudo isso demonstra que Lívia tinha uma "carreira" como esposa de Augusto e sugere que ela possuía um senso político acurado, levando-a a um considerável poder e influência. Provavelmente, a posição que Lívia conquistou veio do seu círculo de contatos estabelecido pelo Patronato. No leste da Grécia, começou a receber honras depois que foi deificada. A importância de Lívia na divulgação da identidade imperial é indicada pelo fato de que ela também foi uma das primeiras a aparecer nas moedas provinciais orientais, por volta do ano de 16 a.C. O próprio Augusto nunca retratou Lívia em nenhuma de suas cunhagens romanas oficiais. Ela era a silenciosa esposa obediente nos bastidores, nunca na vanguarda (Zager, 2014, 
pp. 54-57). Entretanto, acabou retratando seus filhos, Caio César, Júlia e Lucio César, sendo que os dois eram filhos de Júlia, mas foram adotados por Augusto, demonstrando harmonia e prosperidade familiar através de seus futuros herdeiros.

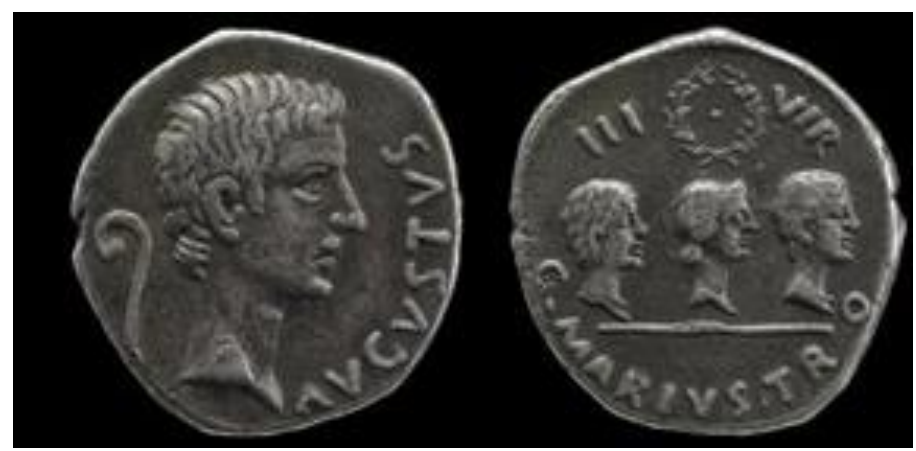

Fig. 03. Denário de prata, datado de 13 a.C., cunhado em Roma, com 3,48g, com o rosto de Augusto voltado à direita no anverso, além da inscrição: AUGUSTUS; observa-se no reverso os três filhos de Augusto, Caio César, Julia e Lucio César, com a inscrição: C.MARIVS.TRO III VIR ${ }^{15}$ (César Mario.

Terceiro triunvirato). ${ }^{16}$

Créditos: (C) The Trustees of the British Museum

De outra maneira, Tibério, filho de Lívia com Tibério Cláudio Nero e filho adotivo de Augusto, sabia da importância de sua mãe, que depois de sua morte tornou-se Júlia Augusta, adotada pela família Juliana e deificada. Ele também sabia da consideração que o povo tinha por Lívia ${ }^{17}$ e concedeu com que o Senado aprovasse cunhar sua imagem, mas negou várias titulações a ela.

\footnotetext{
${ }^{15}$ Número de referência no museu: 1921,0612.1. Bibliografia: RE1 106, p. 21, RIC1 404, p. 72. Catálogo C\&M:

RE1p21.106.(https://www.britishmuseum.org/research/collection_online/collection_object_details.aspx?o bjectId=1214000\&partId=1\&images=true, recuperado de 10 de novembro, 2019).

16 Tradução nossa.

${ }^{17}$ Essa informação não quer dizer que Tibério não tinha desavenças com sua mãe, mas que utilizou da imagem dela para seus desígnios propagandísticos.
} 


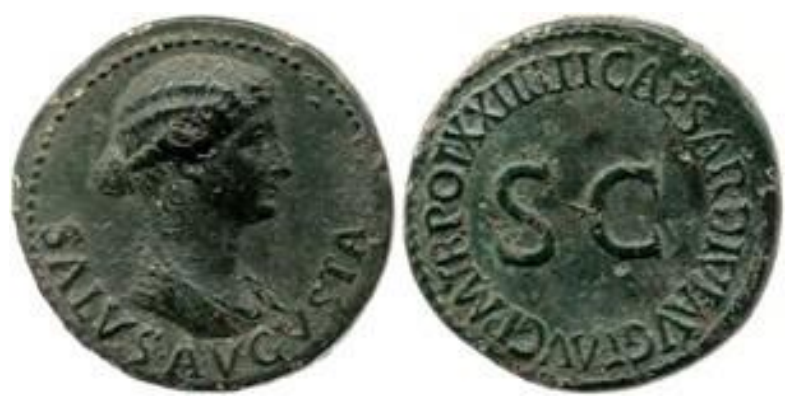

Fig. 04 - Dupondio de Lívia ou Júlia Augusta como Salus, com o rosto voltado à direita, cunhada em Roma, datada de 22 - 23 d.C., de bronze, com 28 mm de diâmetro, peso de 14,06g, de durante o governo de Tibério, 14 - 29 d. C. Legenda: SALVS AVGVSTA (Salo Augusta ${ }^{18}$ ); Legenda do reverso: TI CAESAR DIVI AVG F AVG TR POT XXIIII/S C = Tiberius Caesar Divi Augustus Fili Augustus Pontifex Maximus Tribunicia Potestate Vicesimum Quartum (Tibério César Augusto, Filho do Divino Augusto, Maior Sumo Pontífice encarregado do Vigésimo Quarto Poder Tribunário); ${ }^{19}$ Legenda maior do reverso: S(enatus) C(onsultum) (cunhada pelo consentimento do Senado $\left.{ }^{20}\right) \cdot{ }^{21}$

Créditos: () The Trustees of the British Museum

Agripina Maior, neta de Augusto, que queria seu marido Germânico no trono de Roma, tornou-se ativa dentro da carreira de seu marido e se preocupou com sua própria imagem pública (Zager, 2014, p. 82). Além disso, ela também desejava ver seus filhos no poder e sua homenagem veio nos tempos de Calígula, seu filho, em honra a quem o ajudou a estar no poder. De acordo com os Anais de Tácito, ela é caracterizada de início como "determinada," o que era uma boa característica, adicionada à fidelidade ao marido. Foi elogiada pelo autor como inteligente e educada, descrição que mudou ao longo da narrativa, quando ele passou a caracterizá-la como uma mulher feroz, raivosa, violenta e emotiva (Tacitus, Annals, $1.33 ; 1.69 ; 4.12 ; 4.52 ; 4.51-2 ; 5.3 ; 6.25)$.

\footnotetext{
18 Tradução nossa.

19 (https://en.numista.com/catalogue/pieces65997.html, recuperado em 07 de março,2019).

20 Tradução nossa.

${ }^{21}$ Número de registro: R.6361. Referência bibliográfica: RIC1 47, p. 97; RE1 83, p. 131. Catálogo C\&M: RE1p131.83.

(https://www.britishmuseum.org/research/collection_online/collection_object_details.aspx?objectId=120 2443\&partId=1, recuperado em 10 de novembro, 2019).
} 

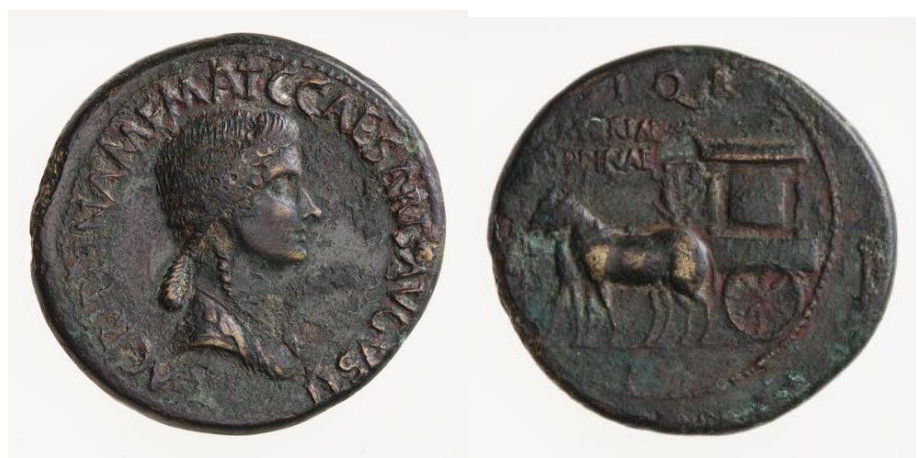

Fig. 05 - Sestertio com o busto drapeado de Agripina Maior olhando para a direita, cunhada em Roma, de bronze, com peso de 25,18g, sob o governo de Calígula, 37 - 41 a.C. Legenda no anverso: AGRIPPINA M F MAT C CAESARIS AVGVTI = Agrippina Marci Filia Mater Caii Caesaris Augusti (Agripina, Filha de Marcus, Mãe de Caio César Augusto); Legenda do reverso: $S$ P Q R / MEMORIAE / AGRIPPINAE=

Senatus Populus Que Romanus (O Senado e o povo romano), Memoriae Agrippinae (À memória de

$$
\text { Agripina } \left.^{22}\right) \cdot{ }^{23}
$$

Créditos da imagem: (C) Heath Warwick; Fonte: Museums Victoria; Direito autoral: Museums Victoria. ${ }^{24}$

No reverso da figura demonstrada há um carpetum, considerado uma honra e uma recompensa pelo privilégio patriótico, visto que até mesmo Messalina e Agripina Menor faziam uso dele na cidade apenas em ocasiões especiais (Zager, 2014). Para acrescentar, diferentemente das moedas de Otávia, esta moeda de Agripina Maior é exclusivamente em sua homenagem, sem a presença do governante, demonstrando a ênfase e devoção de Calígula à sua mãe, a qual o ajudou a conseguir o poder.

A filha de Germânico com Agripina Maior, que se chamava Agripina Menor, nasceu na família imperial por volta de 14 d.C., tendo Augusto como seu bisavô e Tibério como seu tio-avô. Primeiramente, foi reconhecida como uma das irmãs de Calígula e, depois, como a esposa de Cláudio e a mãe de Nero. Tácito insistiu em ressaltar as impropriedades da sexualidade de Agripina, sendo uma delas o próprio casamento com Claudio, que era seu tio, irmão mais velho do seu pai (Barrett, 1996, pp. 100-101), ato que, segundo as leis de Roma, consistia em um incesto. Tácito declara que essa relação era ilícita, que eles não deveriam ousar celebrar as núpcias da devida forma e que não

22 (https://en.numista.com/catalogue/pieces65992.html, recuperado em 07 de março, 2019).

${ }^{23}$ ID: 81000988. Referências: RIC 055 (Gaius), Trillmich Group II (026/R - [uslisted rev. Die]), Classical Numismátic Group (http://www.cngcoins.com/Coin.aspx?CoinID=140534 http://www.coinproject.com/coin detail.php?coin=268261, recuperado em 06 de março, 2019).

24 (https://collections.museumvictoria.com.au/items/66390, recuperado em 11 de novembro, 2019). 
Mare Nostrum, ano 2020, v. 11, n. 1 .

tinha tido precedentes para a introdução de uma sobrinha na casa do tio. Tal ato era, definitivamente, um incesto, declarou Tácito (Tacitus, Annals, 11.5).

Vitelio, no discurso para o Senado, em defesa desse casamento, explicou que um casamento com a filha do irmão era uma novidade para eles, mas que isso era comum em outros lugares e que não tinha lei para proibir. Continuou afirmando que casamentos entre primos antes eram desconhecidos, mas naquela época já eram frequentes, na medida em que o costume se adaptava à conveniência, de modo que essa novidade iria ocupar, futuramente, lugar entre os usos reconhecidos (Tacitus, Annals, 12.6). Sendo assim, os senadores aprovaram o casamento da filha de Germânico e a união passou a ser vista como apaziguadora de futuros conflitos para a sucessão. Para Tácito, isso representou uma profunda degeneração moral, assim como o casamento de Otávia com Nero, que, conforme o autor, foi a causa de todas as calamidades seguintes (Barrett, 1996, pp. 101102), pois Nero foi adotado por Claudio e passou a ser como um irmão para sua filha, Otávia.

Para Tácito, o casamento de Claudio significou a posse efetiva de Agripina no poder, sendo que nos relatos seguintes, do ano de 50 a 54 d.C., esse assunto é dominante, uma vez que o autor descreve a atividade da esposa em benefício do seu filho Nero e seu privilégio em receber o título de Augusta (Tacitus, Annals, 12, 25-26; 12, 41-43), além do casamento, em 53 d.C., de seu filho com Otávia e, em 54 d.C., do assassinato de Claudio, por Agripina, para garantir o trono a Nero (Tacitus, Annals, 12, 64-69). Dessa forma, para Tácito, quem governava era Agripina e a ênfase dada "às relações pessoais e familiares e o efeito deletério do domínio de quem deveria ser subalterno" (uma mulher, Agripina) "fica evidente como motor da História para Tácito” (Funari \& Garraffoni, 2016, p. 125). Ao mencionar sobre a exibição da luta de gladiadores, Tácito questiona como um príncipe, com seus meros dezessete anos, poderia lutar e evitar tal perigo, referindo-se a Agripina, bem como questiona como os romanos poderiam recorrer a alguém que era dominado por uma mulher (Tacitus, Annals, 13.6). Um dos poucos momentos que Tácito declara que a influência de Agripina sobre seu filho Nero estava enfraquecendo foi quando ele se apaixonou por uma mulher liberta, Acte (Tacitus, Annals, 13.12).

De acordo com Barrett (1996), Dião Cássio declarou que Agripina tinha Claudio em seu controle e que, para Tácito, esse casamento representava uma transformação no desenvolvimento do Estado de Roma, pois as relações estavam agora no controle de uma 
mulher, mas não uma mulher como Messalina, que utilizou o poder apenas para consumir excessos, tendo em vista que seu desejo não era por paixão, e sim por poder. Tácito a concebia como uma pessoa austera, totalmente livre de conduta promíscua, senão para contribuir para seu poder. Até a ganância dela é vista pelo autor como um dispositivo para reforçar o seu domínio. Dião Cássio menciona que, depois do casamento, Agripina começou a ter total controle sobre o marido com uma mistura de intimidação e suborno. A tática dela era arranjar um homem livre para persuadir Claudio a seguir os conselhos dela. Além disso, Dião Cássio expressa a passividade de Claudio, que estava certo de que Agripina traria ao casamento um senso político aguçado (Barrett, 1996, pp. 102-103).

Em 49, Agripina estava casada com o imperador de Roma e tinha noivado seu filho com a filha do seu marido. Seu sucesso ainda foi significativamente simbolizado com o recebimento do título de Augusta em 50 d.C. Ela foi a primeira esposa de imperador vivo a receber esse título. Lívia, por exemplo, também recebeu o mesmo título, mas já era viúva (Barrett, 1996, p. 108).

Agripina envenenou Claudio para colocar Nero no poder (Tacitus, Annals, 12.66). Segundo Tácito, Pallas, um liberto, sugeriu que Claudio tinha arruinado a si mesmo, através de um casamento incestuoso e pela adoção fatal de um filho (Tacitus, Annals, 13.2). 

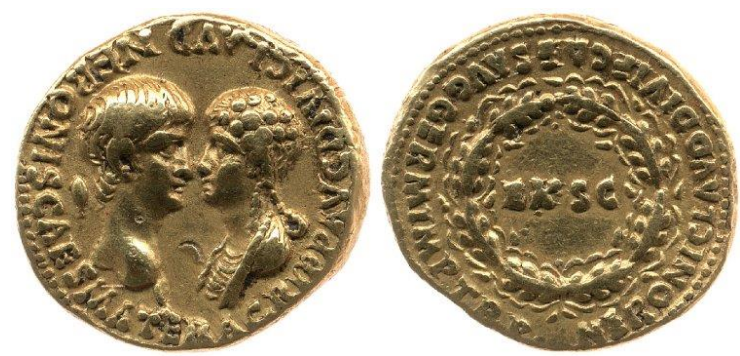

Fig.06. Aureus, de 7,63g, datada de 54 d.C., do governo de $\mathrm{Nero}^{25}$, Legenda: AGRIPP AVG DIVI CLAVD NERONIS CAES MATER (Agripina Augusta, esposa do divino Cláudio e mãe de Nero César ${ }^{26}$ ); Legenda do reverso: NERONI CLVD DIVI F CAES AVG GERM IMP TR P / EX S C (Imperador Nero César

Augusto Germânico, filho do divino Cláudio, com poder tribunário / cunhada de acordo com o consentimento do Senado $)^{27}$, com uma coroa de carvalho. ${ }^{28}$

Crédito: $\odot$ The Trustees of the British Museum ${ }^{29}$

A influência dominante de Agripina, que é demonstrada na moeda anterior, exemplifica-se pelo fato de que seu retrato compartilha o anverso com o imperador (seu filho) e apenas seu título aparece. Os dizeres $E X S C$ no reverso são uma evidência da extensão da prerrogativa senatorial à cunhagem de metais preciosos. Entretanto, por mais que o anverso demonstre apenas sua indicação, pela citação AGRIPP AVG DIVI CLAVD NERONIS CAES MATER, seu nome é acompanhado dos nomes de Cláudio e Nero, confirmando a ligação que ela tinha com eles, sugerindo que sua posição não dependia de si própria, mas da anuência dos imperadores.

\footnotetext{
${ }^{25}$ Número de referência no museu: R.6509. Bibliografia: RE1 2, p. 200, RIC1 3, p. 150. Número no catálogo C\&M:RE1p200.2.

(https://www.britishmuseum.org/research/collection_online/collection_object_details.aspx?objectId=121 6066\&partId=1, recuperado em 10 de novembro, 2019).

${ }^{26}$ (http://www.forumancientcoins.com/numiswiki/view.asp?key=AGRIPP\%20AVG\%20DIVI\%20CLAV D\%20NERONIS\%20CAES\%20MATER\%20EX\%20S\%20C, recuperado em: 08 de março, 2019).

${ }^{27}$ Tradução nossa com consulta. (http://www.forumancientcoins.com/board/index.php?topic=51364.0, recuperado em 08 de março, 2019).

${ }^{28}$ ID: 76001396. Referência: RIC 002 (original de Roma), WCN 36, Classical Numismatic Group. Denominação: denário. (http://www.cngcoins.com/Coin.aspx?CoinID=109071 e http://www.coinproject.com/coin_detail.php?coin=283510, recuperado em 06 de março, 2019).

${ }^{29}$ (https://www.britishmuseum.org/research/collection online/collection object details.aspx?objectId=12 16066\&partId=1, recuperado em 11 de novembro, 2019).
} 


\section{Conclusão}

Pode-se concluir que as imagens reproduzidas nas moedas deveriam ser algo aceitável para os padrões de representação que o público teria como expectativa, ou seja, o tipo de figura teria que ser algo que demonstrasse que a família imperial era bem cultivada ou bem-sucedida, e, no caso específico das mulheres, elas deveriam ser reportadas evidenciando suas virtudes domésticas. Muito provavelmente, essas imagens deveriam ter sido feitas com intenções políticas, de autopropaganda e de controle.

As imagens das mulheres imperiais teriam que seguir os valores daquele tempo, ostentando a amostragem das virtudes daquelas mulheres, para serem um benefício ao governante. $\mathrm{O}$ imperador, ao consentir a cunhagem das moedas com a figura feminina de sua família, fazia com que as virtudes dela fossem de acordo com uma moral, detendo essas imagens sob seu controle. Nessa perspectiva, as moedas confirmam uma dimensão da variedade histórica de formação de gênero, a qual é uma construção social transmitida para uma comunidade através de certos veículos de significados e símbolos (Riess, 2012, pp. 499-500).

Essas normas e valores podem ser considerados significantes à formação das identidades sociais, que constituíram a sociedade romana daquele tempo. No caso desse artigo, tratou-se de demonstrar a diferença atribuída ao homem e a mulher da elite da sociedade romana, nas atuações do público e do privado. As moedas demonstram as imagens dos membros femininos da família imperial, que foram controladas de tal maneira que suas figuras foram divulgadas em favor de uma propaganda política, social e androcêntrica, deixando de demonstrar quem essas mulheres realmente eram. 
Mare Nostrum, ano 2020, v. 11, n. 1 .

\section{REFERÊNCIAS BIBLIOGRÁFICAS}

Fontes:

Cassio Dio. (1914-27). Roman History. (E. Cary, trad.). W. Heinemann.

Plutarch. (1965). Mark Antony. In: I. Scott-Kilvert (translated and introduction), Makers of Rome. Penguin Books.

Tacitus, P. C. (1952). The Annals and The Histories. (J. A. Church, W. J. Brodribb \& J. Great, trads.). Penguin Classics.

Estudos:

Balandier, g. (1980). O poder em cena. EDUnB.

Barrett, A. A. (1996). Agrippina: sex, power, and politics in the early empire. Yale University Press.

Bélo, T. P. (2014). Boudica e as facetas femininas ao longo do tempo: nacionalismo, feminismo, memória e poder. [Tese de doutoramento, Universidade Estadual de Campinas].

Bélo, T. P. \& Funari, P. P. A. (2017). As romanas e o poder nos Anais de Tácito. Clássica: Revista Brasileira de Estudos Clássicos. 30 (2), 75-90.

Bilge, S. (2009). Théorisations féministes de l'intersectionnalité. Diogène, 1 (225), 7088.

Bielman, A. (2012). Female patronage in the Greek Hellenistic and Roma Republican periods. In: S. L. James \& S. Dillon (Eds.). A companion to women in the ancient world. Willey-Blackwell.

Bobbio, N. et al. (Org.). (1986). Dicionário de política. EDUnB.

Brennan, P. (2007). Faces of power. In: P. Brennan, M. Tunner \& L. Wright (Orgs.). Faces of power: imperial portraiture on Roman coins. The University of Sidney. 
Busino, G. (1980). Propaganda. In Enciclopedia Einaudi. Giulio Einaudi, 11, 275-295.

Deniaux, E. (2006). Patronage. In N. Rosenstein \& R. Morstein-Marx (Eds.). A companion to the roman republic. Blackwell Publishing Ltd.

Dixon, S. (1983). A family business: women's role in patronage and politics at Rome, 80 - 44 B.C. Classica et Mediaevalia, 34, 91-112.

Filho, E. P. \& Vasconcelos, E. (2007). Foucault: da microfísica à biopolítica. In M. Rago \& A. L. Martins (Orgs). Revista aulas: dossiê Foucault, 1 (3), 1-22.

Fischler, S. (1994). Social Stereotypes and Historical Analysis: the case of the imperial women at Rome. In Women in Ancient Societies (pp. 115-133). Routledge.

Florenzano, M. B. (1991). Vigiar e Punir: Nascimento da Prisão. (9 ed.). Vozes.

Florenzano, M. B. (2015). A moeda romana na Antiguidade: uma introdução à história e aos significados das emissões monetárias. In M. B. Florenzano, A. M. Ribeiro \& V. L. Monaco (Orgs.). A coleção de moedas romanas da Universidade de São Paulo, Museu Paulista, Museu de Arqueologia e Etnologia. MAE/USP.

Foucault, M. (2001). História da sexualidade I: a vontade de saber. (14 ed). Graal.

Fustel de Coulanges, N. D. (1890). Les origines du système feodal. Hachette.

Gardner, J. F. (1990). Women in Roman law and society. Routledge.

Godechot, J. (1952). La propagande. Annales, 34, 515-517.

Gonçalves, A. T. M. (2002). A construção da imagem imperial: formas de propaganda nos governos de Septímio Severo e Caracala. [Tese de pós-graduação, USP].

Gonçalves, A. T. M. (2014). Entre gregos e romanos: história e literatura no mundo clássico. Revista Tempo, 20. 1-14.

Harvey, T. (2020). Julia Augusta: images of Rome's first empress on the coins of the Roman empire. Routledge: Tayor \& Francis Group.

Hidalgo de La Vega, M. J. (1995). El intellectual, la realeza y el poder politico en el imperio romano. Ediciones Universidad. 
Mare Nostrum, ano 2020, v. 11, n. 1 .

Hodder, I. (1986). Reading the past: current approaches to interpretation in archaeology. Cambridge University Press.

Huici Modenes, A. (1996). Estrategias de la persuasión: mito y propaganda política. Alfar.

Kergoat, D. (1978). Ouvriers = ouvrières? Propositions pour une articulation théorique de deux variables: sexe et classe sociale. Critiques de l'Économie Politique, 5, 6597.

Kergoat, D. (2010). Dinâmica e consubstancialidade das relações sociais. Novos Estudos Cebrap, 86, 93-103. [Em francês: Dynamique et consubstantialité des rapports sociaux In E. Dorlin (Org.). Sexe, race, classe: pour une épistémologie de la domination (pp. 111-125). Actuel Marx Confrontations, 2009].

Laplantine, F. \& Trindade, L. (1997). O que é imaginário. Brasiliense.

Levick, B. (1982). Propaganda and the Imperial coinage. Antichthon 16, 107-108.

Maia, A. C. B. (2005). Identidade e papéis sexuais: uma discussão sobre gênero na escola. In C. C. B. Maia \& A. F. Maia (Orgs.). Sexualidade e Infância. Cadernos Cecemca, 1. Cecemca MEC/SEF, 66-82.

Mazza, M. (1970). Lotte sociali e restaurazione autoritaria nel III Secolo d.C. University of Winsconsin.

Mead, M. (1969). Sexo e temperamento. Perspectiva.

Meyers, R. (2012). Female portraiture and female patronage in the high imperial period. In S. L. James \& S. Dillon (Eds.). A companion to the women in the Ancient World (pp. 453-466). Blackwell Publishing.

Nolasco, S. (1993). O mito da masculinidade. Rocco.

Omena, L. M. (2007). Os Ofícios: Meios de Sobrevivência dos Setores Subalternos da Sociedade Romana. Fenix: Revista de História e estudos culturais, 4 (1). Universidade de São Paulo, 01-13.

Pereira, M. E. (2002). Psicologia social dos estereótipos. EPU. 
Porto, V. C. (2012). As moedas romanas da Península Ibérica e da Síria-Palestina: uma tentativa de diálogo. Mare Nostrvm - Estudos sobre o Mediterrâneo Antigo. n. 3, $13-32$.

Porto, V. C. (2014). A cidade como discurso ideológico: monumentalidade nas moedas do Império Romano. Revista do Museu de Arqueologia e Etnologia. Supl., 18, 93101.

Porto, V. C. (2018). O culto imperial e as moedas do Império Romano. Phoînix, 24 (1), $138-154$.

Rawson, B. (2006). Finding roman women. In N. Rosenstein \& R. M. Marx (Eds.) A companion to the roman republic (pp. 324-341). Blackwell Publishing.

Reis, K. C. F \& Maia, A. C. B. (2009). Estereótipos sexuais e a educação sexista no discurso de mães. In T. G. M. Valle (Org.). Aprendizagem e desenvolvimento humano: avaliações e intervenções (pp. 137-154). Cultura Acadêmica.

Revell, L. (2016). Ways of being roman: discourses of identity in the roman west. Oxbow Books.

Riess, W. (2012). Rari exempli femina: female virtues on Rome. In S. L. James \& S. Dillon (Orgs.). A companion on women in the Ancient World (pp. 491-501). WileyBlackwell.

Sampaio, A. O. \& Venturini, R. L. B. (2009). Uma breve reflexão sobre a família na Roma Antiga. VI Jornada de Estudos Antigos e Medievais - Trabalhos Completos Disponível em: http://www.ppe.uem.br/jeam/anais/2007/trabalhos/030.pdf. (recuperado em 07 de novembro de 2015).

Shanks, M. \& Tilley, C. (1992). Reconstructing Archaeology: theory and practice. $\left(2^{\text {nd }}\right.$ ed.). Routledge.

Sordi, M. (Ed.). (1974). Contributi dell'Istituti di Storia Antica. Università Cattolica del Sacro Cuore.

Souza, F. C. (2006). Meninos e meninas na escola: um encontro possível? Zouk. 
Mare Nostrum, ano 2020, v. 11, n. 1 .

Spencer-Wood, S. (1999). Gendering power. In T. Sweely (Ed.). Manifesting power: gender and the interpretation of power in archaeology (pp. 175-183). Routledge.

Sutherland, C. H. V. (1986). Compliment or complemente? Dr. Levick on Imperial coin types. Numismatic Chronicle ${ }_{2}$ 146, 85-93.

Tunner, M. (2007). Foreword. In P. Brennan, M. Tunner \& L. Wright (Orgs.). Faces of power: imperial portraiture on Roman coins. The University of Sidney.

Wallace-Hadrill, A. (1986). Image and authority in the coinage of Augustus. Journal of Roman Studies, 76, 67-68.

Whitaker, D. C. A. (1995). Menino - Menina: sexo ou gênero? In R. V. Serbino \& Grande (Orgs.). A escola e seus alunos: o problema da diversidade cultural (pp. 31-52). Unesp.

Wood, S. E. (1999). Imperial women: a study in public images, 40 BC-AD 68.Brill's Scholars' List.

Zager, I. (2014). The political role of women of the Roman elite, with particular attention to the autonomy and influence of the Julio-Claudian women (44 BCE to CE 68). [ degree of Master of Arts, University of South Africa].

Zenhas, A. (2007). Estereótipos de gênero. Disponível em: https://www.educare.pt/opiniao/artigo/ver/?id=11982\&langid=1 recuperado em 27 de abril de 2017). 


\section{IMPERIAL WOMEN's COINS}

Taís Pagoto Bélo

\section{ABSTRACT}

This article aims to explore the public image of some of the women from the Late Republic/Early Empire displayed in coins dated from the Principality, established by Augustus (27 BC) until the death of Nero (68 AD). It is intended to illustrate how, during this period, these women enhanced their visibility in public life, through tasks linked to the imperial family, which led them to the Patronage and, consequently, to self-propaganda, which was a way of displaying power.

Women of that time were restricted to a private and domestic life due to the existence of the patria potestas, which was significant and marked the father's power relations within the Roman family, classifying women as unequal to the man. The conquest of women in having their names remembered, through statues, plaques, and coins was something recent at the end of the Republic and the beginning of the Empire, established through the Patronage. The memory of the person, in this way, was something important and could reverberate for generations in the family.

Coins with representations of imperial women make it possible not only to chronologically reconstruct their existence in history, but also to demonstrate that they were active in public life

\section{KEYWORDS}

Imperial women; coins; Rome. 